\title{
One-and-a-half syndrome in ischaemic locked-in state: a clinico-pathological study
}

\author{
J BOGOUSSLAVSKY, ${ }^{*}$ J MIKLOSSY, $†$ F REGLI, ${ }^{*}$ JP DERUAZ, $†$ PA DESPLAND ${ }^{*}$
}

From the Service de Neurologie* (1) and Division de Neuropathologie (2), $\dagger$ Centre Hospitalier Universitaire Vaudois, Lausanne, Switzerland

SUMMARY Five patients with "locked-in" syndrome and dysconjugate palsy of horizontal gaze were studied. In all cases internuclear ophthalmoplegia due to dysfunction or destruction of the median longitudinal fasciculus was combined with an ipsilateral gaze palsy, producing the "oneand-a-half" syndrome. Clinical and electro-oculographic examination suggested involvement of the paramedian pontine reticular formation when all ipsilateral saccades were abolished, when exotropia of the contralateral eye was present, and when vestibular stimulation showed full conjugate deviation to the damaged side. Involvement of the abducens nucleus was suggested when the palsy of ipsilateral gaze was not dissociated on vestibular stimulation. In three cases these clinical deductions were confirmed by the pathological study, which showed a corresponding destruction of the median longitudinal fasciculus, paramedian pontine reticular formation and abducens nucleus. In one case the one-and-a-half syndrome evolved into a total horizontal gaze palsy, which corresponded to involvement of the abducens nucleus contralateral to the initially destroyed paramedian pontine reticular formation. Vertical oculocephalic response disappeared, because of destruction of the median longitudinal fasciculus on both sides (bilateral internuclear ophthalmoplegia). Patients with the locked-in syndrome provide a unique situation in which complex pontine oculomotor disturbances may be studied, because consciousness is preserved. In these patients, dissociated and dysconjugate oculomotor palsy may have been underestimated.

Plum and Posner ${ }^{1}$ introduced the term "locked-in" syndrome to describe a neurological state consisting in tetraplegia, paralysis of all lower cranial nerves and of horizontal gaze, leaving the patient with only vertical eye movements and blinking to indicate his fully preserved consciousness. The first report of a case with locked-in syndrome was probably made by Darolles $^{2}$ in 1875 . Ventral pontine lesions are the most frequent cause..$^{2-10}$ Clinical variants with different types of oculomotor disturbances have been reported, ranging from the preservation of all eye movements ${ }^{3-51112}$ to the association with abnormal vertical movements. ${ }^{813}$ Dysconjugate and dissociated horizontal gaze palsy have been reported rarely in locked-in syndrome. ${ }^{6714}$ In five patients suffering from locked-in syndrome we found a palsy of hori-

Address for reprint requests: Dr Bogousslavsky, Service de Neurologie, CHUV, 1011 Lausanne, Switzerland.

Received 21 February 1984

Accepted 17 March 1984 zontal gaze which consisted of the "one-and-a-half" syndrome. ${ }^{15}$ In the one-and-a-half syndrome an internuclear ophthalmoplegia is combined with a lateral gaze palsy to the same side, so that the ipsilateral eye is fixed in the midposition and the contralateral eye can only abduct from and return to the midline. It has been suggested that different unilateral or bilateral pontine lesions may be responsible for the one-and-a-half syndrome, involving the median longitudinal fasciculus, the paramedian pontine reticular formation, and the nucleus or intrapontine fibres of the abducens nerve. ${ }^{16}$ Our study adds three more cases with oneand-a-half syndrome with necropsy findings to the eight already published, ${ }^{14-21}$ and shows evidence for clinical variants in the one-and-a-half syndrome, according to the structures involved.

\section{Case reports}

Case 1. A 50-year-old man with hypertension suffered 


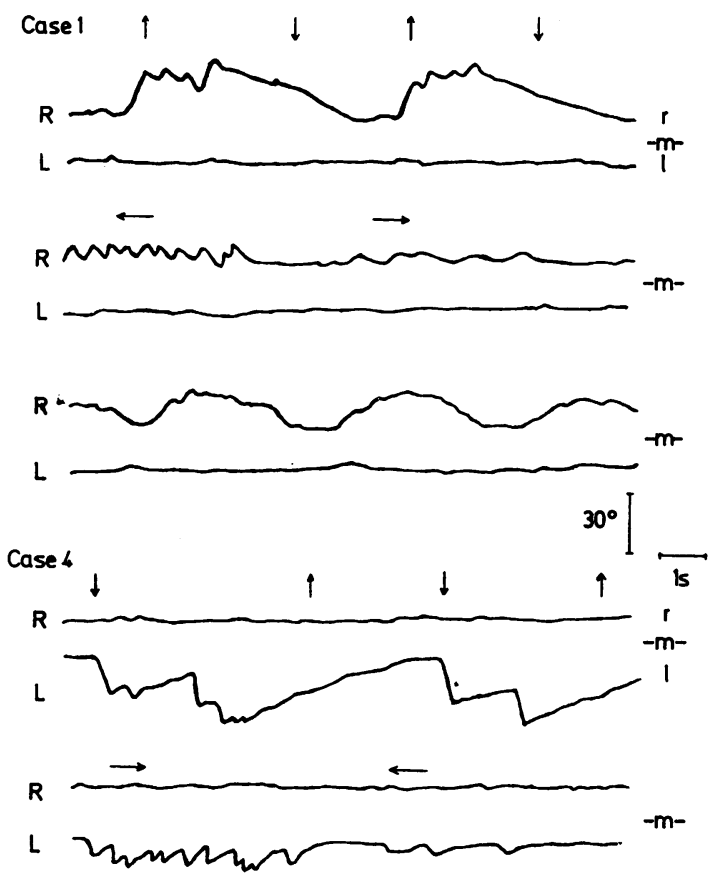

$\mathbf{R}$

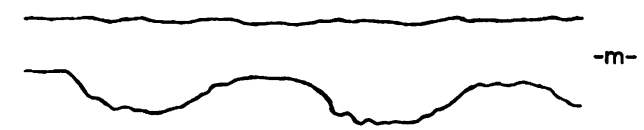

Fig 1 Horizontal eye movements. Case 1 and case 4 (lines 1 and $2=$ voluntary saccades, lines 3 and $4=O K N$, lines 5 and 6 = foveal smooth pursuit movement, $R=$ right eye, $L$ $=$ left eye, $r=$ right, $l=$ left, $m=$ midline, $\uparrow=$ voluntary saccade to the right, $\downarrow=$ voluntary saccade to the left, $\rightarrow=$ right stimulation for $O K N, \leftarrow=$ left stimulation for $O K N$ ). Case 1: Note the absence of leftward saccades (voluntary and $O K N$ ) for the right eye. The exotropic right eye can only drift back to the midline and abduct again on foveal pursuit. The left eye is fixed in the midline. Case 4: Note the absence of rightward saccades (voluntary and $O K N$ ) for the left eye. The exotropic left eye can only return to and abduct from the midline on foveal pursuit. The right eye is fixed in a midposition.

nausea and dizziness for 3 weeks, before awaking with a left hemiplegia sparing the face, right facial palsy and limb dysmetria. Babinski signs were present bilaterally. After 2 days he developed exotropia of the right eye associated with diplopia, followed by a rapidly progressive tetraplegia with palsy of the lower cranial nerves. Consciousness was not altered, and the patient could communicate through eyes blinking.

Oculomotor findings: Horizontal eye movements were recorded separately for each eye (AC electro-oculography, time constant of 2 seconds): voluntary saccades, foveal smooth pursuit movements, optokinetic nystagmus (OKN) (elicited by alternating white and black stripes moving across a screen situated one meter in front of the patient) (fig 1). No vestibular-induced movement was recorded. The left eye remained in the midline for all attempted lateral movements. The right eye was tonically deviated to the right and could not cross the midline on attempted gaze to the left. Extreme abduction elicited a right-beating nystagmus. For this eye, voluntary saccades to the right appeared normal, but the velocity of "rapid" eye movements (voluntary or OKN) to the left did not exceed $15 \%$ and could not be called a "saccade". Horizontal foveal pursuit movements of the right eye were moderately saccadic. During oculocephalic movement, both eyes could fully deviate to the left and the right eye to the right. Convergence was possible but depressed. Vertical movements appeared normal. A computed tomography scan (CT) showed a bilateral hypodense area in the pons (fig 2), suggesting infarction. CSF was normal. The left vertebral artery was not detected on retromastoidal Doppler ultrasonography. The patient steadily improved during the next 6 months, and became able to walk alone with sticks. He recovered phonation, swallowing, and facial movements, and had a normal mental state. The exotropia of the right eye disappeared after 2 weeks, but without notable change in the oculomotor palsy.

Case 2 A 53-year-old obese woman had suffered intermittent ataxia and dizziness for 3 years. She suddenly fell in her kitchen, without loss of consciousness, and was admitted to hospital. Neurological examination showed dysarthria, paraplegia, and paralysis of the left face and arm. Anticoagulant therapy was started, but after 10 hours the patient developed tetraplegia with palsy of the lower cranial nerves. Eye blinking was retained on command. The pupils were $1 \mathrm{~mm}$ in diameter and reactive.

Oculomotor findings (not recorded): the right eye remained fixed in the midline during all voluntary or foveal pursuit attempts. The left eye was in a midposition and could only abduct from and return to the midline. The movements were not slowed. OKN to the left showed a very small but adequate response for the left eye. OKN to the right was normal for this eye. The oculocephalic movement showed isolated abduction from and return to the midline for the left eye. Convergence was preserved, as were vertical movements. A CT scan (fig 2) showed a bilateral pontine hypodense area, mostly paramedian, suggesting infarction. The right vertebral artery was not detected on retromastoidal Doppler ultrasonography. The patient's condition slowly improved, and after one year she was able to speak and to use her left arm. Oculomotor disturbances had disappeared. After 3 years the patient could walk with sticks, do some washing and prepare the meals for her husband.

Case 3 This 57-year-old man had experienced headaches and scintillating scotomas for 6 months, before referral for progressive dysarthria, nausea, tinnitus, ataxia and bilateral facial numbness. Neurological examination revealed a spontaneous left-beating horizontal nystagmus, left miosis, decreased sensation in the upper part of the left hemiface, paresis of the left arm with hyperactive tendon reflexes, and deviation to the left in the Romberg test. After 3 days a right conjugate gaze palsy developed, with worsening of the left-sided weakness, which extended to the inferior 


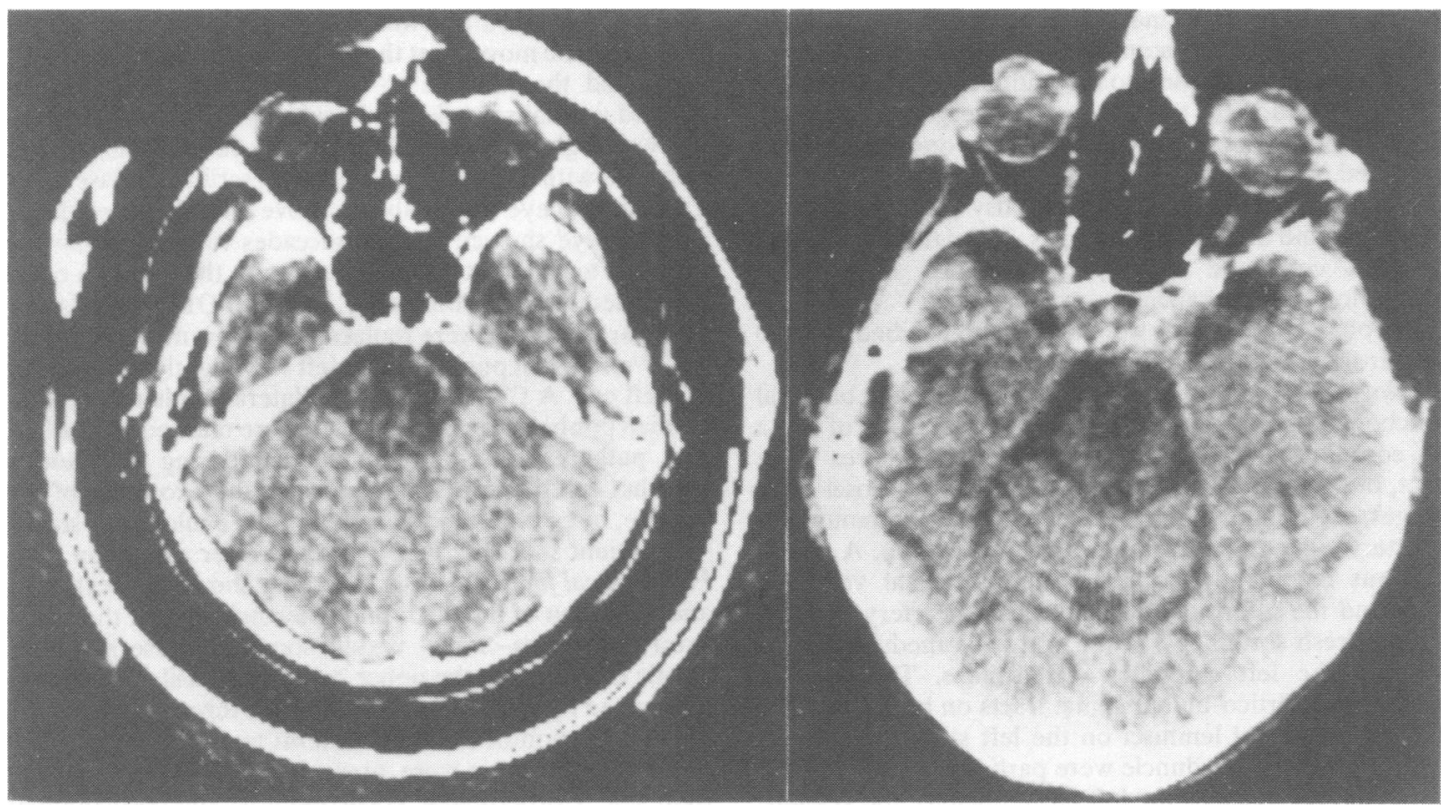

Fig 2 Computed tomography Case 1: Bilateral hypodense area in the pons, suggesting infarction. Case 2: Bilateral paramedian pontine hypodense area, suggesting infarction.
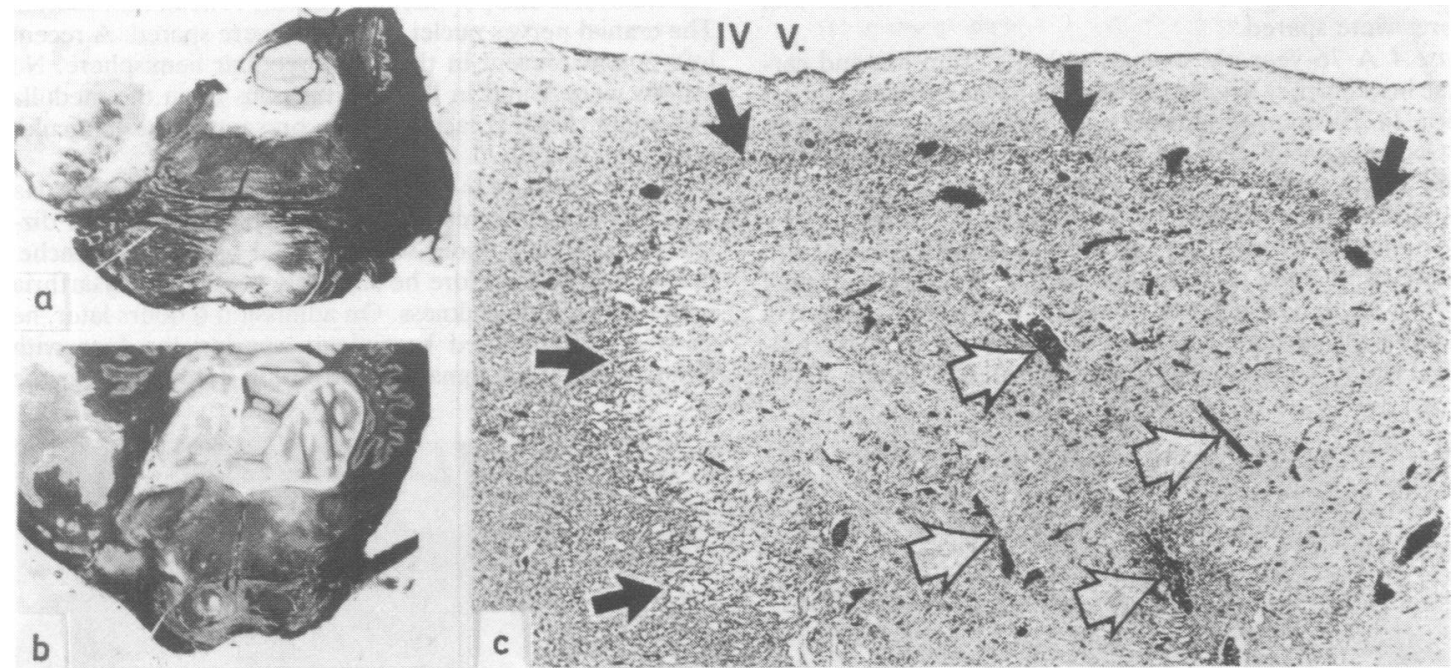

c

Fig 3 Case 3, transverse sections through the pons (Loyez) (A) Level of the trigeminal nerve: destruction of the right basis of the pons and the left middle cerebellar peduncle. (B) Level of the abducens nuclei: destruction of the right abducens nucleus. Lesions of the right paramedian pontine reticular formation and present but less marked. (C) Histological picture of the lesions of the right abducens nucleus: fourth ventricle (IV V.) lined by a layer of ependymal cells. Black arrows indicate the boundaries of the infarct, with several dilated vessels (clear arrows).

limb. Intravenous anticoagulant therapy was started. After 1 day the patient showed a marked exotropia of the left eye.

Oculomotor findings (not recorded): the right eye remained in the midline for all attempted lateral move- ments. The left eye could return to the midline (without crossing it) from the exotropic position only with a very smooth movement (which took 2-3 seconds). Abduction of this eye was achieved much more rapidly, with a leftbeating nystagmus in extreme lateral position. For this eye, 
OKN to the left was normal, whereas no OKN to the right could be elicited. Horizontal oculocephalic movements showed isolated adduction to the midline and return to the abducting position for the left eye. Convergence and vertical movements were preserved. After one day hiccup developed, followed after another day by a rapidly progressive tetraplegia and a complete palsy of facial, lingual, pharyngeal and masticatory muscles. The patient could still blink on command with persistence of the former oculomotor disturbances, except that horizontal oculocephalic movements were abolished. He died after 10 hours from a cardiopulmonary arrest.

Pathological findings (fig 3): necropsy showed bilateral bronchopneumonia and moderate atherosclerosis of aorta and coronary arteries. The cerebral hemispheres were intact, but the intra-cranial vessels showed atherosclerotic changes, predominating in the right posterior communicating artery, which showed severe stenosis $(80 \%)$. A recent thrombus completely occluded the left distal vertebral artery and the inferior third of the basilar artery, causing multiple fresh softenings, in the pons, the medulla oblongata and the left cerebellar hemisphere. The corticopontine, and cortico-bulbar/spinal tracts on both sides, the median and lateral lemnisci on the left side, and the left superior cerebellar peduncle were partially destroyed. The right abducens nucleus, the left facial nucleus, the vestibular nuclei bilaterally, and the right paramedian pontine reticular formation were also involved. Both median longitudinal fasciculi, oculomotor and trochlear nuclei and fibres were spared.

Case 4 A 76-year-old woman with hypertension and cardiac insufficiency developed left-sided weakness and dysarthria in 10 hours, followed by a sudden worsening with tetraplegia, facial diplegia, inability to speak or to swallow. The pupils were $1 \mathrm{~mm}$ in diameter and reactive. The patient remained conscious, and was able to blink.

Oculomotor findings: the left eye was tonically deviated to the left and could not cross the midline on attempted gaze to the right. On extreme abduction, this eye showed a left-beating nystagmus. The right eye was fixed on the midline, being unable to do any lateral movement. Con- vergence occurred but was of a small amplitude. During oculocephalic movement the eyes could fully deviate to the right, and the left eye to the left. Vertical movements showed normal saccades and oculocephalic response; pursuit was slightly saccadic. Horizontal eye movements were recorded with the same method as described in case 1 (fig 1). The right eye was unable to move laterally or medially. The left eye showed normal saccades to the left, but no saccades to the right (from abduction to the midline) could be elicited, neither voluntarily, nor with OKN. In this eye, rightward saccades were replaced by a slow movement $\left(10^{\circ}\right.$ $-20 \%$ s). Foveal pursuit to the left was slightly saccadic for the left eye. A CT scan showed bilateral median and paramedian pontine hypodense areas, more marked on the left. The patient's state did not change during the next 3 months, except for disappearance of the exotropia of the left eye, but without modification of the oculomotor status. The patient suddenly died 13 weeks after admission.

Pathological findings (fig 4): necropsy showed hypertrophy and dilatation of the heart and atherosclerosis of the aorta. Intra- and extra-cranial vessels showed diffuse atherosclerotic changes and the upper half of the basilar artery was obstructed by an organised recanalised thrombus. Bilateral cystic infarction of the crura cerebri and of the upper and middle basis pontis were present, predominating on the right side. Corticospinal, corticopontine and corticobulbar fibres were destroyed. The lesions extended to the tegmentum pontis, with involvement of the right median longitudinal fasciculus and paramedian pontine reticular formation. The cranial nerves nuclei and fibres were spared. A recent infarct was present in the left cerebellar hemisphere. No lesions were found in the inferior pons or in the medulla oblongata. Several lacunes were present in the lenticular nuclei bilaterally.

Case 5 This 46-year-old hypertensive man with type IIa hyperlipoproteinaemia suffered transient episodes of dizziness, bilateral colored scotomas and occipital headache, during 3 months before he suddenly developed dysarthria with a left-sided weakness. On admission 6 hours later, he showed a right-sided hemiplegia sparing the face with bilateral Babinski signs, and deviation of the eyes to the

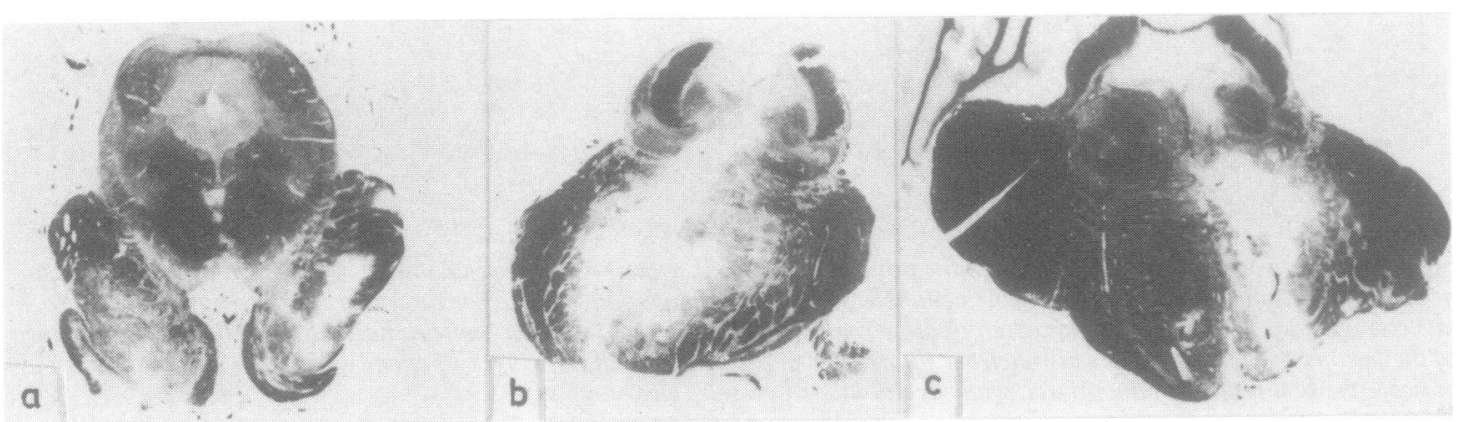

Fig 4 Case 4, transverse sections through the mesencephalon $(A)$ and the upper pons $(B$ and $C)($ Loyez) (A) Both cerebral peduncles are destroyed by the infarct. The tectum and tegmentum are spared. $(B)$ The lesions extend to the paramedian part of the basis of the pons. In the tegmentum, the right median longitudinal fasciculus and paramedian pontine reticular formation are involved. The left paramedian pontine reticular formation shows only minor recent alterations. (C) The lesions are limited to the right side, with involvement of the median longitudinal fasciculus, paramedian pontine reticular formation and corticofugal fibres. 
right, associated with a left conjugate gaze palsy. Intravenous anticoagulant therapy was started. However, after 2 days, the patient became tetraplegic, with a complete paralysis of all movements except blinking and some eye movements. A bilateral miosis $(0.5 \mathrm{~mm})$ was present. Consciousness was preserved and communication occurred through the blinking movements.

Oculomotor findings (not recorded): the left eye remained fixed in the midline. The right eye was exotropic, and could only return to the midline, before again abducting. The velocity of these movements was not evaluated. For this eye, OKN to the right was normal, but it could not be elicited to the left. Oculocephalic movements showed normal abduction of the right eye and conjugate crossing of the midline to the left for both eyes, without reaching the extreme position. After one week, examination showed that total horizontal gaze palsy had developed, with disappearance of exotropia of the right eye. Horizontal oculocephalic manoeuvre showed isolated and partial abduction of the left eye. Vertical oculocephalic manoeuvre did not elicit eye movements, but voluntary vertical movements were still preserved. A CT scan showed a hypodense area in the median and paramedian pons. The patient died 3 weeks after admission from bilateral pneumonia.

Pathological findings (fig 5): at necropsy only the brain was examined. Extra- and intra-cranial vessels showed moderate to severe atherosclerotic changes. The lower half of the basilar artery was thrombosed. In the brainstem, corticospinal, cortico-pontine and cortico-bulbar fibres were destroyed bilaterally at different levels. Both the median longitudinal fasciculus, the right abducens nucleus and the left paramedian pontine reticular formation were involved, but the left abducens nucleus and the right paramedian pontine reticular formation showed minor alterations. Microscopi- cally, the areas of infarction were of different ages, the oldest being in the left pons and medulla, with macrophages, neovessels, and axonal swelling.

\section{Discussion}

The one-and-a-half syndrome combines internuclear ophthalmoplegia with an ipsilateral horizontal gaze palsy, and is related to lesions involving the paramedian structures of the dorsal pons. ${ }^{14-21}$ Eight cases with pathologic study have been reported in the literature (table 3 ), most often from pontine infarction due to thrombosis of the basilar artery (or its branches), ${ }^{14} 1517$ spasm, ${ }^{19}$ or without evident cause. ${ }^{20}$ Malignant glioma ${ }^{18}$ or haemorrhage ${ }^{21}$ may also be responsible. In 21 reported cases without pathological study, the presumed aetiology was infarction, $161822-25$ spontaneous or traumatic haemorrhage,,$^{2126-28}$ angioma, $^{24}$ glioma, ${ }^{16182429}$ metastasis, ${ }^{16}$ and multiple sclerosis. ${ }^{162530}$ Only one case was associated with locked-in syndrome. ${ }^{14}$ In the present study, we report five cases with lockedin syndrome and permanent or regressing oneand-a-half syndrome, all related to pontine infarction, in three cases from proved basilar or vertebral thrombosis. Evaluation of oculomotor disturbances suggested that various clinical types of this dysconjugate gaze palsy may occur. Anatomical correlation was provided in three patients.

It has been recently suggested that the horizontal gaze palsy present in one-and-a-half syndrome may be due to ipsilateral destruction of the paramedian
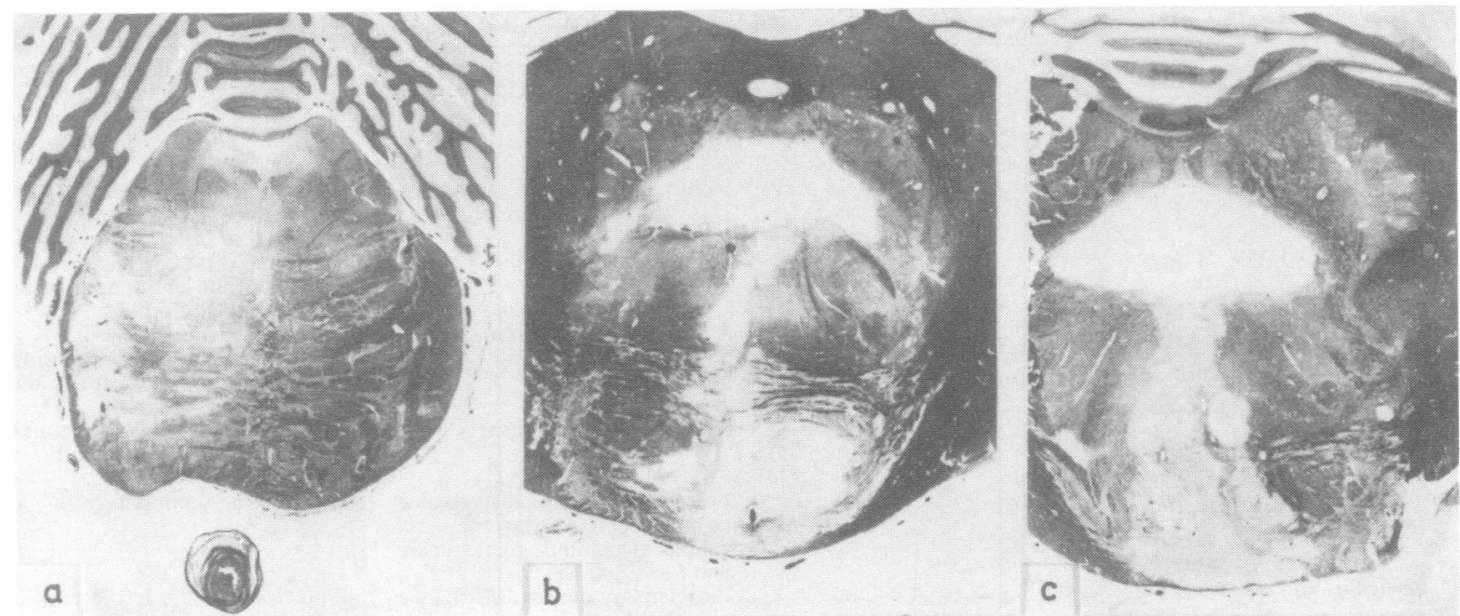

Fig 5 Case 5, transverse sections through the pons (Loyez) (A) Upper pons: the left part of the basis of the pons is destroyed but only minor changes are present in the tegmentum. Note the thrombosis of the basilar artery. $(B)$ Level of the abducens nuclei: massive infarction of the basis of the pons. The right median longitudinal fasciculus, right abducens nucleus, and left paramedian pontine reticular formation are involved. The right paramedian pontine reticular formation shows only minor changes. (C) Lower pons: the left paramedian pontine reticular formation and both median longitudinal fasciculus are destroyed by the infarct. The right paramedian pontine reticular formation shows minor alterations. 
Table 1 Oculomotor findings in 5 cases with locked-in syndrome

\begin{tabular}{|c|c|c|c|c|c|c|c|}
\hline & $\begin{array}{l}\text { Palsy of } \\
\text { ipsilateral } \\
\text { gaze }\end{array}$ & $\begin{array}{l}\text { Ipsilateral } \\
\text { internuclear } \\
\text { ophthalmoplegia }\end{array}$ & $\begin{array}{l}\text { Saccades directed } \\
\text { towards the } \\
\text { damaged side } \\
\text { (voluntary; OKN) }\end{array}$ & $\begin{array}{l}\text { Exotropia of } \\
\text { contralateral } \\
\text { eye }\end{array}$ & $\begin{array}{l}\text { Deviation towards } \\
\text { the damaged side } \\
\text { on oculocephalic } \\
\text { manoeuvre }\end{array}$ & $\begin{array}{l}\text { Preservation of } \\
\text { convergence }\end{array}$ & $\begin{array}{l}\text { Preservation of } \\
\text { vertical saccades }\end{array}$ \\
\hline Case 1 & + & + & - & + & + & $(+)$ & + \\
\hline Case 2 & + & + & + & - & - & + & + \\
\hline Case 3 & + & + & - & + & - & + & + \\
\hline Case 4 & + & + & - & + & + & $(+)$ & + \\
\hline
\end{tabular}

+ present, (+) decreased or slowed, - absent.

Table 2 State of pontine oculomotor structures

\begin{tabular}{|c|c|c|c|c|c|c|}
\hline & \multicolumn{2}{|c|}{$\begin{array}{l}\text { Median } \\
\text { longitudinal } \\
\text { fasciculus }\end{array}$} & \multicolumn{2}{|c|}{$\begin{array}{l}\text { Abducens } \\
\text { nucleus }\end{array}$} & \multicolumn{2}{|c|}{$\begin{array}{l}\text { Paramedian } \\
\text { pontine reticular } \\
\text { formation }\end{array}$} \\
\hline & $R$ & $L$ & $R$ & $L$ & $R$ & $L$ \\
\hline Case 3 & - & - & + & - & + & - \\
\hline Case 4 & + & - & - & - & + & - \\
\hline Case 5 & + & + & + & $(+)$ & $(+)$ & + \\
\hline
\end{tabular}

pontine reticular formation, or the abducens nucleus, or both of these structures, or exceptionally of fibres of the abducens nerve combined with destruction of the contralateral median longitudinal fasciculus. ${ }^{1631}$ However, in a detailed electrooculographic study, anatomical confirmation was provided in only one case (unilateral destruction of the median longitudinal fasciculus, paramedian pontine reticular formation, and abducens nucleus. ${ }^{16} \mathrm{On}$ clinical grounds, dysfunction of the paramedian pontine reticular formation may be suspected in oneand-a-half syndrome when all saccades ipsilateral to the lesion are abolished (even in the contralateral hemifield of movement), when the eyes can cross the midline towards the lesion on oculocephalic manoeuvre, and when exotropia of the contralateral eye is present (paralytic pontine exotropia). ${ }^{162431-30}$ Destruction of the abducens nucleus produces a complete ipsilateral gaze palsy without preservation of ipsilateral deviation on oculocephalic movement, and usually without spontaneous deviation of the eyes, thus without exotropia in one-and-a-half syndrome. ${ }^{162431-40}$

Taking these points in turn, three of our cases (cases 1, 4 and 5) showed electro-oculographic or

Table 3 One-and-a-half syndrome: cases with post mortem examination

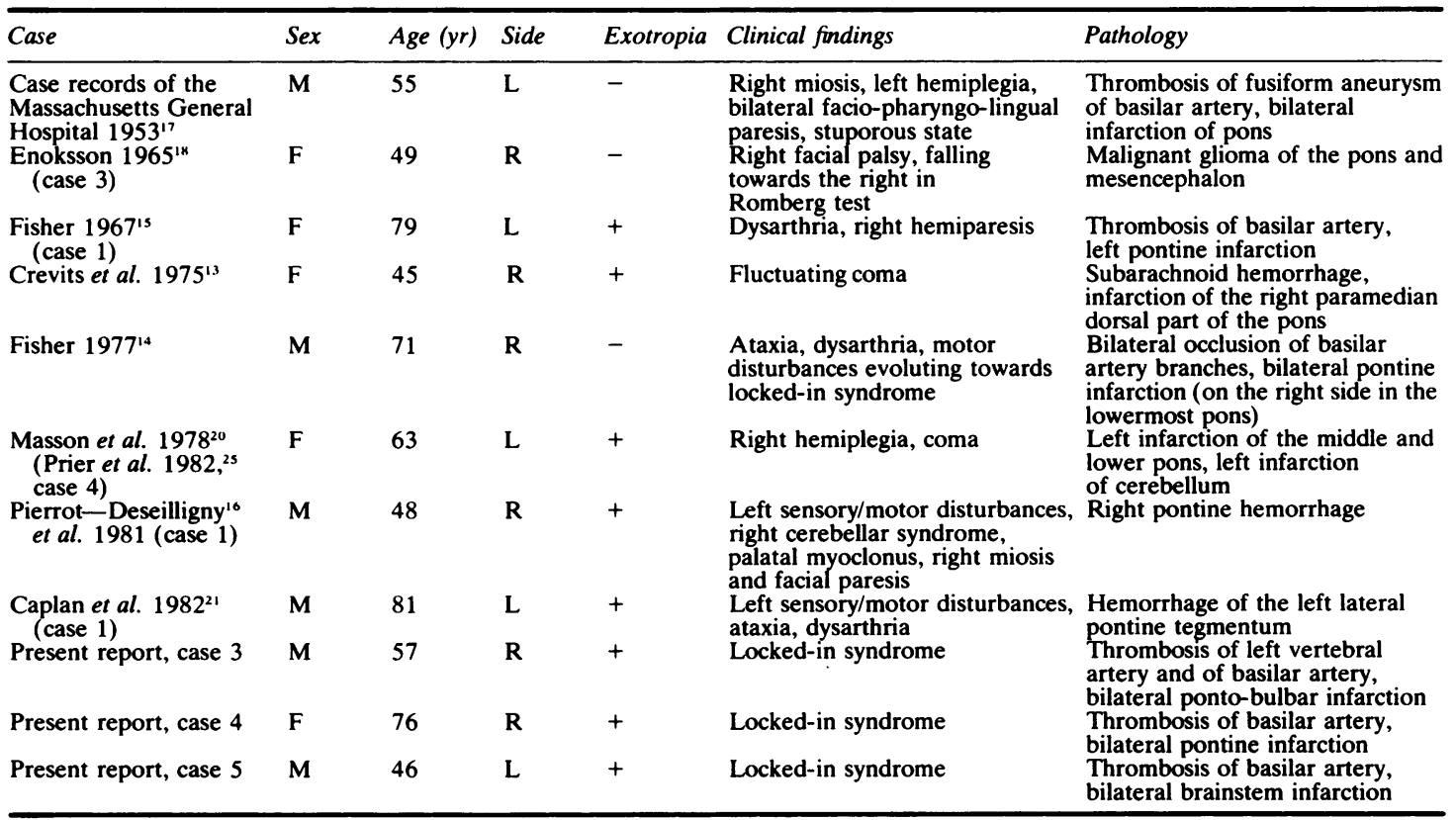


clinical evidence of unilateral dysfunction of the median longitudinal fasciculus and paramedian pontine reticular formation. They showed exotropia of the contralateral eye and absence of all rapid movements ipsilaterally directed in this eye, the other eye showing a total horizontal gaze palsy. In cases 1 and 4 , and initially in case 5 , dissociation of the ipsilateral gaze palsy on oculocephalic manoeuvre suggested preservation of the abducens nucleus. Case 5 deserves more consideration, because of the extraordinary evolution of the oculomotor disturbances. Firstly, this patient showed a left gaze palsy with conjugate deviation to the right, before he developed a left one-and-a-half syndrome. Finally, he developed a total horizontal gaze palsy, except for preservation of a slight abducting movement of the left eye on oculocephalic manoeuvre, with abolished vertical oculocephalic response. The brainstem showed destruction of the median longitudinal fasciculus bilaterally, of the right abducens nucleus, and of the left paramedian pontine reticular formation. The left abducens nucleus and the right paramedian pontine reticular formation showed minor changes. According to these findings, the clinical evolution may be explained by initial destruction of the left paramedian pontine reticular formation (gaze palsy to the left with preserved oculocephalic response), followed by destruction of the left median longitudinal fasciculus (one-and-ahalf syndrome on the left side), and finally by destruction of the right median longitudinal fasciculus and abducens nucleus (total horizontal gaze palsy with preserved abducting movements of the left eye on oculocephalic manoeuvre). In this state, abolition of vertical oculocephalic deviations with relative preservation of vertical voluntary gaze may be related to bilateral destruction of the median longitudinal fasciculus. ${ }^{371}$

In our case 4 , gaze palsy to the right and abolishing of all saccades to the right as well as exotropia of the left eye suggested that the right paramedian pontine reticular formation was involved. Right internuclear ophthalmoplegia suggested involvement of the right median longitudinal fasciculus, and normal horizontal vestibulo-ocular reflex to the right suggested that the right abducens nucleus was preserved. These points were confirmed by the necropsy findings, which showed infarction of the right paramedian pontine reticular formation and median longitudinal fasciculus without involvement of the right abducens nucleus.

Our case 2 showed clinical oculomotor disturbances suggesting unilateral destruction of the median longitudinal fasciculus and abducens nucleus on the right side (the palsy was not dissociated on vestibular stimulation). Presence of saccades to the right for the left eye suggested an intact paramedian pontine reticular formation.

Our case 3 showed clinical evidence for combined dysfunction of the median longitudinal fasciculus, paramedian pontine reticular formation and abducens nucleus on the right side, because of exotropia of the left eye, absence of all rightward saccades (paramedian pontine reticular formation), and absence of dissociation of the gaze palsy on vestibular stimulation (abducens nucleus). In fact the brainstem showed involvement of the right paramedian pontine reticular formation and abducens nucleus. Terminal complete disappearance of horizontal oculocephalic movements could be attributed to bilateral destruction of vestibular nuclei. The median longitudinal fasciculus did not show significant changes; because one-and-a-half syndrome developed extremely acutely, and the patient died only a few hours later, we suggest that dysfunction of the right median longitudinal fasciculus was produced by oedema or pressure ${ }^{21}$ without local infarction.

Our 5 cases suffered from the locked-in syndrome. In the locked-in syndrome, other oculomotor disturbances than one-and-a-half syndrome have usually been reported: complete palsy of horizontal gaze, in the "classic" locked-in syndrome, ${ }^{16-942}$ unilateral gaze palsy with contralateral deviation, ${ }^{7}$ bilateral internuclear ophthalmoplegia, ${ }^{43}$ bobbing, ${ }^{79}$ skew deviation, ${ }^{9}$ bilateral ptosis with palsy of third nerve ${ }^{44}$ unilateral third nerve palsy, ${ }^{45}$ abnormal vertical movements, ${ }^{813}$ and also normal oculomotor function. ${ }^{3-51112}$ Bilateral horizontal gaze palsy with preserved oculocephalic response has been described in two cases, ${ }^{67}$ suggesting preservation of the abducens nucleus. Persisting oneand-a-half syndrome has been reported only once,,$^{14}$ but without analysis of oculomotor disturbances. Our study suggests that the frequency of one-anda-half syndrome may be under-estimated in lockedin syndrome. Occurrence of one-and-a-half syndrome in locked-in syndrome corresponds to asymetrical destruction of the dorsal pons, whereas the ventral pons is involved bilaterally to produce tetraplegia.

Occurrence of one-and-a-half syndrome has no prognostic significance in locked-in syndrome; three patients died less than 3 months after admission. The other two cases survived and made a partial but useful recovery. Recovery from locked-in syndrome has been reported ${ }^{46}$ but the condition is generally lethal. In our cases, we did not find a relationship between favourable outcome and lower age or the presence of vertebrobasilar insufficiency ${ }^{46}$ but those patients with multiple vascular risk factors (hypertension, hyperlipidaemia, smoking) did not survive. 
Our study shows that clinical evaluation of ocular movements allows a very precise topographical diagnosis. Clinical differentiation of dysfunciton of the paramedian pontine reticular formation, abducens nucleus, median longitudinal fasciculus and abducens fibres may be accurately achieved. Patients with locked-in syndrome, because of their preserved consciousness, provide an exceptional situation for studying the complex oculomotor disturbances due to brainstem destruction. Systematic clinico-anatomic studies of ocular movements should be undertaken in these cases.

Addendum. Since completion of this work, a clinical study of the one-and-a-half syndrome has been published, with physiopathological deductions, but without neuropathologic studies (Wall M, Wray SH: The oneand-a-half syndrome. A unilateral disorder of the pontine tegmentum: a study of 20 cases and review of the literature. Neurology (NY) 1983;33:971-80).

\section{References}

' Plum F, Posner JB. In: Davis FA, ed. The Diagnosis of Stupor and Coma. Philadelphia: 1966.

${ }^{2}$ Darolles M. Ramollissement de la protubérance: thrombose du tronc basilaire. Progr Med 1875;3:629-30.

${ }^{3}$ Fang $\mathrm{HCH}$, Palmer JJ. Vascular phenomena involving brainstem structures. A clinical and pathologic correlation study. Neurology (Minneap) 1956;6:402-19.

${ }^{4}$ Cravioto H, Silberman J, Feigin I. A clinical and pathologic study of akinetic mutism. Neurology (Minneap) 1960;10:10-21.

${ }^{5}$ Kemper TL, Romanul FCA. State resembling akinetic mutism in basilar artery occlusion. Neurology (Minneap) $1967 ; 17: 74-80$.

${ }^{6}$ Halsey JH, Ceballos R, Crosby EC. The supranuclear control of voluntary lateral gaze. Clinical and anatomic correlation in a case of ventral pontine infarction. Neurology (Minneap) 1967;17:928-33.

${ }^{7}$ Nordgren RE, Markesbery WR, Fukuda K, Reeves AG. Seven cases of cerebromedullospinal disconnection: the "locked-in" syndrome. Neurology (Minneap) 1971;21:1140-8.

" Hawkes $\mathrm{CH}$. "Locked-in" syndrome: report of seven cases. Br Med J 1974;4:379-82.

'Dehaene I, Martin JJ. "Locked-in" syndrome. A clinico-pathological study of two cases. Eur Neurol 1976; 14:81-9.

${ }^{10}$ Bauer G, Gerstenbrand F, Rumpl E. Varieties of the locked-in syndrome. J Neurol 1979;221:77-91.

"Gauthier G. Contribution à l'étude de la thombose basilaire. Schweiz Arch Neurol Neurochir Psychiat 1962;90:209-234.

12 Karp JS, Hurtig HI. "Locked-in" state with bilateral midbrain infarcts. Arch Neurol 1974;30:176-8.

${ }^{13}$ Larmande P, Hénin D, Jan M, Elie A, Gouazé A. Abnormal vertical eye movements in the Locked-in syndrome. Ann Neurol 1982;11:100-2.
${ }^{14}$ Fisher CM. Bilateral occlusion of basilar artery branches. J Neurol Neurosurg Psychiatry 1977; 40:1182-9.

is Fisher CM. Some neuro-ophthalmological observations. J Neurol Neurosurg Psychiatry 1967;30:383-92.

${ }^{16}$ Pierrot-Deseilligny C, Chain F, Serdaru M, Gray F, Lhermitte F. The "one-and-a-half" syndrome. Electro-oculographic analyses of five cases with deductions about the physiological mechanisms of lateral gaze. Brain 1981;104:665-99.

${ }_{17}$ Case records of the Massachusetts General Hospital 1953;249:776-80.

${ }^{18}$ Enoksson P. Internuclear ophthalmoplegia and paralysis of horizontal gaze. Acta Ophthalmol 1965;43:697707.

${ }^{19}$ Crevits L, de Reuck J, Vander Eecken H. Paralytic pontine exotropia in subarachnoid hemorrhage. A clinicopathological correlation. Clin Neurol Neurosurg 1975; 78:269-76.

${ }^{20}$ Masson M, Prier S, Hénin D, Dairou R, PierrotDeseilligny C. Sémiologie neuro-ophtalmologique des lésions protubérantielles. Oto Neuro Ophthalmol 1978;50:107-17.

${ }^{21}$ Caplan LR, Goodwin JA. Lateral tegmental brainstem hemorrhages. Neurology (NY) 1982;32:252-60.

${ }^{22}$ Reuben RN, Gonzalez C. Ocular electromyography in brainstem dysfunction. Arch Neurol 1964;11:265-72.

${ }^{23}$ Fisher CM, Caplan LR. Basilar artery branch occlusion: a cause of pontine infarction. Neurology (Minneap) 1971;27:900-5.

${ }^{24}$ Sharpe JA, Rosenberg MA, Hoyt WF, Daroff RB. Paralytic pontine exotropia. A sign of acute unilateral pontine gaze palsy and internuclear ophthalmoplegia. Neurology (Minneap) 1974;24:1076-81.

${ }^{25}$ Prier S, Larmande P, Hénin D, Delouvrier JJ, Masson M. Le syndrome un et demi de Fisher. Association d'une paralysie de la latéralité et d'une ophtalmoplégie internucléaire antérieure. Etude de 5 cas. $J$ Fr Ophtalmol 1982;5:49-53.

${ }^{26}$ Freeman W, Ammerman HH, Stanley M. Syndromes of the pontile tegmentum. Arch Neurol Psychiatry 1943; 50:462-71.

${ }^{27}$ Smith MS, Buchsbaum HW, Masland WS. One and a half syndrome. Occurrence after trauma with computerized tomographic correlation. Arch Neurol 1980;37:251.

${ }^{28}$ Kase C, Maulsby G, Mohr JP. Partial pontine hematomas. Neurology (NY) 1981;30:652-5.

${ }^{29}$ Kommerell G. Clinical clues for the organization of horizontal quick movements and subsequent periods of fixation. In: Lennerstrand $G$, Bach-y-Rita $P$, eds. Basic Mechanisms of Ocular Motility and their Clinical Implications. New York: Pergamon Press, 1975:325-35.

${ }^{30}$ Bender MB, Weinstein EA. Dissociated monocular nystagmus with paresis of horizontal ocular movements. Arch Ophthalmol 1939;21:266-72.

${ }^{31}$ Bogousslavsky J, Regli F. Exotropie pontique paralytique et non paralytique. Rev Neurol (Paris) 1983; 139:219-23.

${ }^{32}$ Pierrot-Deseilligny C, Prier S, Masson M, Cambier J. Enregistrement des mouvements oculaires chez 
l'homme lors de lésions unilatérales de la formation réticulaire pontique paramédiane. Rev Neurol (Paris) $1978 ; 134: 355-66$.

${ }^{33}$ Pierrot-Deseilligny C, Chain F, Gray F, Escourolle R, Castaigne P. Paralysies supranucléaires de la latéralité d'origine protubérantielle. Rev Neurol (Paris) 1979; 135: 741-62.

${ }^{34}$ Pierrot-Deseilligny C, Chain F, Lhermitte F. Syncrome de la formation réticulaire pontique. Précisions physiopathologiques sur les anomalies des mouvements oculaires volontaires. Rev Neurol (Paris) 1982;138: 517-32.

${ }^{35}$ Henn V, Cohen B. Coding information about rapid eye movements in the pontine reticular formation of alert monkeys. Brain Res 1976; 108:307-25.

${ }^{36}$ Henn V, Büttner U. Disorders of horizontal gaze. In: Lennerstrand G, Zee DS, Keller El, eds. Functional Basis of Ocular Motility Disorders. Oxford: Pergamon Press, 1982.

${ }^{37}$ Henn V, Hepp K, Büttner-Ennever JA. The primate oculomotor system II. Premotor system. A synthesis of anatomical, physiological, and clinical data. Hum Neurobiol 1982;1:87-95.

${ }^{38}$ Goebel HH, Komatsuzaki A, Bender MB, Cohen B. Lesions of the pontine tegmentum and conjugate gaze paralysis. Arch Neurol 1971;24:431-40.

${ }^{39}$ Carpenter MB, McMasters RE, Hanna GR. Disturbances of conjugate eye movements in the monkey $\mathrm{I}$ : physiological effects and anatomical degeneration resulting from lesions of the abducens nucleus and nerve. Arch Neurol 1963;8:231-47.

${ }^{40}$ Meienberg O, Büttner-Ennever JA, Kraus-Ruppert R. Unilateral paralysis of conjugate gaze due to lesion of the abducens nucleus. Clinico-pathological case report. Neuro-Ophthalmol 1982;2:47-52.

${ }^{41}$ Vetterli A, Henn V. Congenital horizontal gaze palsy in two brothers. In: Huber A, Klein D, eds. Neurogenetics and Neuro-ophthalmology, Elsevier/North Holland Biomedical Press, 1981:81-88.

${ }^{42}$ Dehaene I, Dom R. A mesencephalic locked-in syndrome. J Neurol 1982:227:255-9.

${ }^{43}$ Feldman MH. Physiological observations in a chronic case of "locked-in" syndrome. Neurology (Minneap) 1971;21:459-78.

${ }^{44}$ Meienberg O, Mumenthaler M, Karbowski K. Quadriparesis and nuclear oculomotor palsy with total bilateral ptosis mimicking coma. A mesencephalic "locked-in syndrome"? Arch Neurol 1979;36:70810.

${ }^{45}$ Cherington M, Stears J, Hodges J. Locked-in syndrome caused by a tumor. Neurology (Minneap) 1976; 26: $180-2$.

${ }^{46}$ McCusker EA, Rudick RA, Honch GW, Griggs RC. Recovery from the "locked-in" syndrome. Arch Neurol 1982;39:145-7. 